\title{
Formalismo e perda da dimensão humana em A metamorfose de Franz Kafka
}

\author{
Márcio José Coutinho*
}

\begin{abstract}
Resumo: Este trabalho tem o objetivo de analisar o modo como a transformação do personagem Gregor Samsa em barata pode simbolizar a perda da dimensão humana. Para tanto, parte-se da hipótese de que esse aspecto reflete um elemento de premonição em relação ao horror causado pela guerra, elemento este que está associado ao engajamento do autor com a situação política e social de sua época.
\end{abstract}

Palavras-chave: Autoritarismo; Perda da dimensão humana; Engajamento.

\begin{abstract}
This article aims at analyzing how the transformation of the character named Gregor Samsa into a cockroach may symbolize the loss of his human dimension. Therefore, we start considering the hypothesis that this aspect reflects an element of premonition regarding the horror caused by the war, once this element is linked to the author's commitment to the political and social situation of his time.
\end{abstract}

Keywords: Authoritarianism; Loss of human dimension; Commitment

A obra de Franz Kafka é fortemente marcada por um tratamento especial dispensado ao material lingüístico, o que lhe valeu ter sido o trecho inicial de $A$ metamorfose, empregado como modelo exemplar de narrativa por Umberto Eco em seu ensaio "Entrando no bosque" (ECO, 1990). Por outro lado, este traço valeu ao escritor ter sido considerado formalista (o que equivalia a reacionário) pelos críticos do Realismo socialista, movimento literário implantado pelos soviéticos na RDA (HEISE; ROHL, 1986, p. 88).

Ora, o formalismo de Kafka não o impede de ser um escritor engajado, ou seja, de um autor compromissado com sua época. Seu formalismo é, na verdade, o seu realismo, pois, segundo concebe Adorno (apud MERQUIOR, 1969, p. 80): “O realista moderno não tem alternativa senão ser um formalista”. A arte moderna, para Adorno, não corresponde a um espelho do social, "mas sim a um negativo da sociedade" (MERQUIOR, 1969, p. 81). Sendo assim, a essência do verdadeiro realismo está na "deformação" (apud MERQUIOR, 1969, p. 81). Isso equivale a dizer que ao não apresentar uma objetividade, no sentido de uma aproximação em relação ao real, a obra de arte, e em especial a de ficção, logra descortinar o vazio da existência humana.

\footnotetext{
* Márcio Coutinho é aluno do pós-graduação em Letras da Universidade Federal de Santa Maria.
} 
A metamorfose é uma obra cujo formalismo (ou realismo, conforme a concepção adorniana) manifesta-se através da deformação/transformação do protagonista Gregor Samsa em uma barata. Esta deformação/transformação e a sua relação com o caráter formalista da obra serão analisadas na narrativa em questão, tendo em vista a contribuição de tais aspectos para o caráter compromissado deste texto literário. Neste sentido, ressalta-se a hipótese de corresponder a transformação de Gregor Samsa em inseto à perda de sua dimensão humana. George Steiner já afirmava, em um de seus ensaios, que Kafka retratara a redução do homem a um verme atormentado e observara no homem a renascença do bestial (STEINER, 1969, p. 163-164). Este traço pode ser considerado como epifania, pois adianta elementos do horror posteriormente presentes no nazismo, prevendo, por exemplo, a tecnologia das chamadas fábricas da morte - "the technology of the death-factories" (STEINER, 1969, p. 163). O autor ainda destaca que Gregor Samsa, entendido por muitos como um sonho monstruoso, seria o destino literal de milhões de seres humanos (STEINER, 1969, p. 163).

A obra em estudo é um conto simetricamente dividido em três capítulos: no primeiro, narra-se a modificação de Gregor Samsa em barata e as suas primeiras reações em relação à transformação; no segundo, a rendição a essa condição; e no terceiro, o perecimento da personagem. A gradação desses momentos aponta para o sentido de dissolução do protagonista.

Essa perda da dimensão humana é provocada e assegurada por duas instâncias: o trabalho e a família. No primeiro caso, Gregor Samsa (que era caixeiro viajante) estava preso devido a uma dívida da família a um emprego em que o patrão exigia que ele trabalhasse em demasia. Sua rotina impunha-lhe tal irregularidade que ficava constantemente agitado e impossibilitado de criar qualquer vínculo.

Oh, meu Deus, [...] que trabalho tão cansativo escolhi! Viajar, dia sim, dia não. É um trabalho muito mais irritante do que o trabalho do escritório propriamente dito, e ainda por cima há a maçada de andar sempre a viajar, preocupado com as ligações dos comboios, com a cama e com as refeições irregulares, com conhecimentos casuais, que são sempre novos e nunca se tornam amigos íntimos. Diabos levem tudo isto! (KAFKA, 1988, p. 6)

No segundo caso, os membros da família, em um primeiro momento, estão entregues a uma passividade exagerada, deixando que Gregor assuma sozinho a responsabilidade de sustentar a família; em um segundo momento, depois que Gregor já se transformou em 'barata', tratam de assegurar essa condição, afastando-o do convívio familiar, levando-o a ser completamente ignorado enquanto ser humano, identificado, assim sendo, como um inseto imundo.

Gregor Samsa sente-se aprisionado ao seu ofício, como pode ser percebido na seguinte passagem: "Tenho uma dívida de lealdade para com o patrão" (KAFKA, 1988, p. 20). Esta 
frase resume o fato de Gregor sentir a pressão de algo exterior ao indivíduo, que advém dos mecanismos sociais. O personagem precisa viver e agir em função do seu trabalho, o que pode ter relação com o que Karl Marx (1988) denomina reificação: atinge-se tal grau de alienação que o trabalhador perde sua condição de sujeito para o objeto que produz. No caso de Samsa, este se vê alienado não por um objeto, mas pelas condições desumanas do próprio trabalho. A vida de Gregor era controlada por aqueles que estavam acima dele no conjunto de recursos humanos da firma onde trabalhava.

Dessa forma, ele submetia-se aos desmandos do patrão e à pressão do chefe de escritório. Em sua posição de empregado, Gregor era considerado um bem qualquer que deveria funcionar sempre sem que nada perturbasse o seu rendimento. Tal desempenho era assegurado pelas pressões sofridas em sua relação com o patrão e com o chefe de escritório. Isso fica evidente na passagem seguinte:

Senhor Samsa, [...] que se passa consigo? Pára aí barricado no quarto [...] a negligenciar as suas obrigações profissionais de uma maneira incrível! Estou a falar em nome dos seus pais e do seu patrão e peço-lhe muito a sério uma explicação precisa e imediata [...] julgava que o senhor era uma pessoa sossegada, em que se podia ter confiança, e de repente parece apostado em fazer uma cena vergonhosa (KAFKA, 1988, p. 15).

O caráter exaustivo do compromisso de sustentar a família remete a uma situação na qual o protagonista vê-se pressionado a renunciar aos valores individuais. Isso pode ser inferido a partir da seguinte passagem: "Além disso, tenho de olhar pelos meus pais e pela minha irmã" (KAFKA, 1988, p. 20). Esta frase evidencia a renúncia de Gregor aos interesses próprios em nome da responsabilidade de sustentar a família. Porém, ao perder as condições de trabalhador, este personagem é rejeitado como um estorvo.

O pai, ao perceber o estado do filho, parece despertar de sua velhice, tornando-se autoritário e violento, inibindo o que poderia ser uma tentativa de recuperação do filho. Isso pode ser inferido a partir do seguinte trecho:

Impiedosamente, o pai de Gregor obrigava-o a recuar, assobiando e gritando «chô» como um selvagem. Mas Gregor estava pouco habituado a andar para trás, o que se revelou um processo lento. Se tivesse uma oportunidade de virar sobre si mesmo, poderia alcançar imediatamente o quarto, mas receava exasperar o pai com a lentidão de tal manobra e temia que a bengala que o pai brandia na mão pudesse desferir-lhe uma pancada fatal no dorso ou na cabeça (KAFKA, 1988, p. 23).

O gerador torna-se a figura responsável pelo isolamento do personagem. Este afastamento de Gregor é o símbolo da perde da liberdade que antes possuía.

A irmã de Gregor, por seu turno, pode ser considerada o elemento que fornece as condições necessárias para manter o estado em que a integridade humana deste personagem se esvai. No entanto, ao oferecer-lhe "comida própria de um inseto" (KAFKA, 1988, p. 28), ela o exclui enquanto membro da família, tira seu estatuto humano, individual e social, e afirma a 
sua degeneração pela negação de seu direito de manifestar vontade própria. Assim, afirmar a condição de isento de Gregor é torná-lo submisso e fortalecer-lhe à custa dessa submissão.

A irmã, ao tirar a mobília do quarto de Gregor, alegando que ele precisaria de espaço para movimentar-se, colaborava para mantê-lo na condição em que se encontrava. Ela tirava tudo que poderia identificar o irmão a um ser humano, o que, através de uma reminiscência, pudesse levá-lo à recuperação. Por trás de uma máscara de boas intenções, ela o conduzia ao perecimento. Quando Gregor não mais oferece perigo, ela o abandona.

Aos poucos, o protagonista é privado de suas condições concretas de luta contra a situação alienante. Porém, sua presença ergueu-se como uma bandeira contra aqueles que querem seu aniquilamento. A presença de Gregor Samsa incomoda. A força de sua luta está em permanecer na memória. A irmã é, assim, aquela que tenta tirar de Gregor sua identidade: uma vez que um homem deixa de reconhecer-se enquanto tal, lutar deixa de ter sentido. A consciência de Gregor é, porém, a arma que ainda lhe resta. Ele não pode mais falar, mas mantém a capacidade de entender as coisas, discerni-las e revoltar-se contra elas. Por isso, não come a 'comida para barata' que a irmã empurra com o pé para dentro do quarto.

A mãe de Gregor parece ser o único membro da família que nutre algum sentimento que a ligue ao filho; condoendo-se com o seu sofrimento e tentando tomar a sua defesa. Porém, sucumbe passivamente aos argumentos da filha e convence-se de que não pode interceder pelo filho.

Nem sequer havia a certeza de que a remoção da mobília lhe [a Gregor] prestasse um serviço. [A mãe] Tinha a impressão do contrário; a visão das paredes [...] nuas deprimia-a, e era natural que sucedesse o mesmo a Gregor, dado que estava habituado à mobília havia muito tempo e a sua ausência podia fazê-lo sentir-se só (KAFKA, 1988, p. 37-38)

A voz da mãe era o único ‘bem' que dava sentido à vida de Gregor e que despertava nele a necessidade de refletir sobre sua atual situação. Assim, surge para Gregor a pergunta:

Quereria, efetivamente, que o quarto acolhedor, tão confortavelmente equipado com a velha mobília da família, se transformasse numa caverna nua onde decerto poderia arrastar-se livremente em todas as direções, à custa do simultâneo abandono de qualquer reminiscência do seu passado humano? (KAFKA, 1988, p. 38).

Vencida pelos apelos da filha, a mãe ajuda a tirar a mobília do quarto de Gregor Samsa. Este gesto representa a impotência daqueles que mesmo contra seus princípios aderem a uma causa injusta. Em determinado momento, ao perceber que o quarto está quase vazio, Gregor sai do seu esconderijo tentando salvar uma das únicas coisas que pode recuperar o sentido humano de sua vida: o quarto com a figura da mulher envolta em peles pendurado na parede. Este quadro retrata as aspirações de Gregor a fim de recuperar sua essência humana, seu trabalho, sua vida social e a satisfação com a própria vida. Num gesto desesperado, o 
personagem pula sobre a moldura e cola-se sobre o vidro com o objetivo de proteger a última coisa que ainda podia salvá-lo (KAFKA, 1988, p. 40).

Os quadros são as projeções da dimensão humana do protagonista. Estes funcionam como espelhos que mantêm a memória/imagem de um Gregor não-alienado. Tais imagens estão associadas à liberdade que o personagem possuía outrora. Isso se explicita a partir da seguinte passagem:

Mesmo em frente de Gregor, havia uma fotografia pendurada na parede que o mostrava fardado de tenente, no tempo em que fizera o serviço militar, a mão na espada e um sorriso despreocupado na face, que impunha respeito pelo uniforme e pelo seu porte militar. A porta que dava para o vestíbulo estava aberta, vendo-se também aberta a porta de entrada, para além da qual se avistava o terraço de entrada e os primeiros degraus da escada (KAFKA, 1988, p. 20).

A integridade do personagem é associada à liberdade e às várias perspectivas que para ele se abriam, o que pode ser inferido a partir da associação do retrato bem composto com uma porta pela qual se avista a entrada para a rua. Deste modo, o drama de Gregor Samsa resulta da perda de sua liberdade devida à sujeição excessiva aos deveres, o que acabou por privá-lo de seus valores pessoais e humanos.

A princípio, sempre que ouvia menções à necessidade de ganhar dinheiro, Gregor afastava-se da porta e deixava-se cair no fresco sofá de couro [...]. Muitas vezes ali se deixava estar durante a noite, sem dormir, a esfregar-se no couro durante horas a fio. Quando não reunia a coragem necessária para se entregar ao violento esforço de empurrar uma cadeira de braços para junto da janela, trepava para o peitoril e, arrimando-se à cadeira, encostava-se às vidraças, certamente obedecendo a qualquer reminiscência da sensação de liberdade que sempre experimentara ao ver a janela (KAFKA, 1988, p. 33-34).

A partir da análise de A metamorfose, é possível concluir que o distanciamento em relação ao real encontrado na obra exige justamente uma revisão do real. Isso ocorre devido à atmosfera de não-normalidade que emerge das linhas e das entrelinhas da narrativa. Ora, a transformação de Gregor em um inseto exige que se pense as razões disso e que se pergunte o que significa ser um inseto. Neste sentido, retoma-se a afirmação de Adorno: "a deformação é o verdadeiro realismo" (apud MERQUIOR, 1969, p. 81). Pensando em Kafka, é possível afirmar que o disforme é a via pela qual se pode entender o real. Assim, se, por um lado, Kafka foi um formalista, não foi, por outro, menos realista.

\section{Referências}

HEISE, Eloá; RÖHL, Ruth. História da literatura alemã. São Paulo: Ática, 1986.

MERQUIOR, José Guilherme. Arte e sociedade em Marcuse, Adorno e Benjamin. Rio Janeiro: Tempo Brasileiro, 1969. 
KAFKA, Franz. A Metamorfose. Tradução de J. A. Teixeira Aguillar. Santiago: Europa América, 1988.

ECO, Umberto. Seis passeios pelos bosques da ficção. São Paulo: Companhia das Letras, 1990.

MARX, Karl; ENGELS, Friedrich. Fetichismo e reificação In: Sociologia. São Paulo: Ática, 1988. 